\title{
Práticas de Ensino na Comunidade Fundamentadas na Aprendizagem Baseada em Problemassob a Óptica de uma Monitora
}

\author{
Almeida, Thaynara Fontes; Araujo, Jamilly Santos; Fontes, Mírzia Lisboa; Andrade, \\ Maisa Alves; Pinheiro, Frederico Leão \\ Universidade Federal de Sergipe — thaynarafontes@hotmail.com
}

Introdução: a formação de profissionais da saúde requer um ensino de qualidade, que lhe confira competência na realização de atividades assistenciais, gerenciais, de ensino e pesquisa. Pensando nisto, uma universidade do interior de Sergipe adotou a filosofia pedagógica da Aprendizagem Baseada em Problemas (ABP). a ABP é uma metodologia centrada nos alunos onde estes são sujeitos ativos no processo de aprendizagem. Este estudo é um relato de experiência de uma aluna de enfermagem, monitorada subunidade: Práticas de Ensino na Comunidade - PEC - do I Ciclo. o foco desta foi ofertar ao aluno uma nova maneira de ensinar e aprender com o trabalho em equipe multiprofissional que trabalha de forma interdisciplinar e com humanização. para isso, alunos dos cursos de enfermagem, medicina, terapia ocupacional, farmácia, fisioterapia, odontologia e fonoaudiologia cursam o I Ciclo de todas as disciplinas, juntos. Objetivo: Descrever a experiência e o conhecimento adquirido com a monitoria na PEC I. Metodologia: Baseada no arco de Marguerez, os estudos foram iniciados com passeio ambiental, discussão de temas entre instrutor, alunos e monitora como Atenção Primária e Promoção da Saúde, Fundamentos da Atenção Básica à Saúde, Norma Operacional Básica do Sistema Único de Saúde, Norma Operacional da Assistência à Saúde, Histórias da Política de Saúde no Brasil, Planilhas para Planejamento e Programação Local, Leis 8.080 e 8.142, Cidadania, Participação Popular, Determinantes de Saúde e Pacto pela Saúde. Partindo das atividades realizadas e descritas anteriormente, planejamos e executamos ações na comunidade. Resultados: Percebeu-se a importância do trabalho em equipe baseado nos conhecimentos previamente discutidos, os quais proporcionaram uma atuação realista e humanizada na comunidade. Conclusões: É imprescindível a utilização da ABP na formação de profissionais críticos, que trabalhem em equipe multiprofissional e de forma interdisciplinar, conhecedores do Sistema Único de Saúde e humanizados, principalmente quando comparados com aqueles formados no método tradicional, para que o SUS desenvolva-se de forma ideal e consequentemente a população receba uma assistência humanizada e realista.

Almeida, Thaynara Fontes; Araujo, Jamilly Santos; Fontes, Mírzia Lisboa; Andrade, Maisa Alves; Pinheiro,

Frederico Leão. Práticas de Ensino na Comunidade Fundamentadas na Aprendizagem Baseada em Problemassob a Óptica de uma Monitora. In: Anais do Congresso Internacional de Humanidades \&

Humanização em Saúde [= Blucher Medical Proceedings, num.2, vol.1]. São Paulo: Editora Blucher, 2014. ISSN 2357-7282

DOI $10.5151 /$ medpro-cihhs-10720 